\title{
sciendo
}

\section{The Applications of Landing Strategies in Badminton Footwork Training on a Backhand Side Lateral Jump Smash}

\author{
by \\ Min-Hao Hung', Chi-Yao Chang ${ }^{1}$, Kuo-Chuan Lin², Chia-Ling Hung', \\ Chin-Shan $\mathrm{Ho}^{1}$
}

\begin{abstract}
Previous research in badminton has associated unilateral landings following overhead strokes with the occurrence of knee injuries. Smashing involves tensing the abdomen muscles while swinging the racket rapidly and maintaining one's balance while performing coordinated movements and steps; this process puts stress on the player's lower limbs. However, few studies have compared the effects of different stroke training while performing various types of badminton strokes. This study investigated the influence of different stroke training on the smash action of badminton players. Three stroke training conditions were considered: shadow, target striking, and smashing. Sixteen male experienced badminton players were recruited for this study. One-way repeated-measures ANOVA with Bonferroni correction was used to identify the differences. At the initial contact with the ground, the knee flexion and knee valgus angles under the smash condition were significantly higher than target and shadow conditions. Under the smash condition, hip abduction was significantly higher than under the target and shadow conditions. Moreover, the hip abduction under the target condition was significantly higher than under the shadow condition. At the maximum knee flexion, the hip abduction under the smash and target conditions was significantly higher than under the shadow condition. Regarding the time from the moment of initial contact to the peak of vertical ground reaction force it was shorter under the smash condition than the target and shadow conditions. The vertical ground reaction force was higher under the smash condition than under the target and shadow conditions. The $50 \mathrm{~ms}$ impulse was higher under the smash condition than under the target and shadow conditions. The main findings of this study are that under the smash condition, the motion in the frontal plane increased, which produced higher loads on the joints in the lower limbs. Player performed the same footwork under the three conditions, but the landing strategies differed because of unique swing motions and techniques. The condition under which a player hits a shot to a target area can affect the landing. The results of this study suggest that target practice is more effective for improving the landing technique employed during actual shots than shadow practice.
\end{abstract}

Key words: motion analysis, footwork training, lateral jump smash.

\section{Introduction}

Badminton is a high intensity sport in which players must execute an array of movement patterns including jumps, lunges and changes of direction (Kimura et al., 2010; Madsen et al., 2015; Shariff et al., 2009). In previous studies, foot movement was used to evaluate the risk of lower limb injuries and athletic performance in badminton players (Kimura et al., 2012; Kuntze et al., 2010). Moreover, most badminton injuries occur in the lower extremities. Previous research suggested that the injury frequency while playing badminton was 7.1 per 1,000 hours of participation, which was higher than the rate while performing gymnastics (6.8), playing rugby (6.0), or basketball (5.6) (Weir and

1 - Graduate Institute of Sports Science, National Taiwan Sport University, Taoyuan, Taiwan.

2 - Office of Physical Education, Chung Yuan Christian University, Taoyuan, Taiwan.

3 - Physical Medicine and Rehabilitation department, Kaohsiung Veterans General Hospital, Kaohsiung, Taiwan. 
Watson, 1996). Badminton players most commonly face knee injury, followed by back, ankle joint, thigh, and calf injuries (Goh et al., 2013; Miyake et al., 2016; Reeves et al., 2015; Yung et al., 2007). Studies on badminton movement patterns training have mainly focused on landing strategies when performing the lunge at the net (Fu et al., 2017; Kuntze et al., 2010) and the backcourt jump smash (Kimura et al., 2010; Kimura et al., 2012). Badminton has unilateral strokes, and landing strategies vary across directions of the strokes. Previous research has found that most lower limb injuries happen after backhand strokes in the backcourt (Kimura et al., 2012). It was also indicated that one-foot landing postures mostly occurred after backhand roundthe-head strokes. This landing posture exerts a high load on the knee joints, increasing the risk of knee injuries (Kernozek et al., 2005; Kimura et al., 2010; Sasaki et al., 2018; Kanasova et al., 2019). Anterior cruciate ligament (ACL) injuries are one of the most common sports injuries, and $70 \%$ of ACL injuries are noncontact sports injuries incurred during landing and cutting actions (Boden et al., 2009). A considerably large valgus angle at the knee joint while landing can cause knee injuries. The large knee valgus angle increases the pressure on the ACL, thereby increasing the risk of ACL injury (Hewett et al., 2005). Practical application of landing strategies can be affected by several factors. The lateral landing by performing a lateral jump is a crucial factor that induces knee valgus deformity. Previous studies on the landing posture after performing lateral jumps at different angles have reported that the valgus angle at the knee joint varies with changes in the landing direction (Stephenson et al., 2017). Some studies have used motion analysis to assess the risk of lower limb injuries, and one particular study of badminton players placed inertial measurement unit sensors on players' trunk to assess the differences between various badminton actions and paces (Nagano et al., 2018). Another study used inertial measurement unit (IMU) and image analysis to examine the around-the-head stroke performed in the backcourt and determined that backhand strokes resulted in a higher risk of injury (Sasaki et al., 2018). Factors such as gender, changes of direction, and lower limb fatigue can affect landing strategies and cause different lower extremity injuries (Coventry et al., 2006; Hughes et al., 2010; Kernozek et al., 2005; Petersen et al., 2005). Studies indicate that most ACL injuries occur during the landing impact caused after a jump (Arendt and Dick, 1995; Hughes et al., 2010; Schmitz et al., 2007). It has been demonstrated that landing times tend to fall within the range of 25-50 ms, and most ACL injuries occur within 40 ms after the landing (Koga et al., 2010; Krosshaug et al., 2007).

The ability of a badminton player to move appropriately on the court affects the result of a match. During matches, badminton players perform jump smashes based on the velocity of the shuttlecock. The lateral jump smash is a common motion in badminton matches. The lateral jump smash is a backcourt attack move that is a commonly executed technique in doubles matches. Badminton players receive different stroke training for the lateral jump smash. Footwork training is the only form of badminton training that can be performed without an opponent. Footwork training is typically performed with racket swinging, without striking a shuttlecock. If a difference in landing strategies is found between racket swinging and footwork, the effect of training might be reduced.

Landing strategies after a badminton player performed a lateral jump smash were analyzed in this study. Unlike previous studies, the current study compared badminton stroke training with other modes of training. This study aimed to explore the applications of landing strategies while performing smashes, target striking, and shadow training in badminton.

\section{Methods}

\section{Experimental approach to the problem}

Cross-sectional analysis of the posture of male badminton athletes while performing lateral jump smashes was conducted. The kinematic variables of the lateral jump smash tasks (shadow, target striking, and smash action) were evaluated. Players assessed under the three conditions all executed the same footwork. We exhorted these players to perform the actions to the best of their ability. Moreover, the ground reaction force (GRF) test was conducted to evaluate the load on the lower limb. A correlation analysis was used to identify different stroke training associations between kinematic and GRF variables. 


\section{Participants}

Sixteen elite Taiwanese male badminton players were recruited; all the players were right handed. Participants had took part in the quarterfinals of tournaments conducted at the national level. The average age, body height, body mass, and experience in badminton of players were $21.1 \pm 1.9$ years, $174.3 \pm 4.3 \mathrm{~cm}, 68.4 \pm 6.7 \mathrm{~kg}$, and $10.5 \pm 2.4$ years, respectively. Participants reported no history of surgery on the lower limbs or musculoskeletal disorders in a span of 1 year prior to data collection. All procedures were approved by the Institutional Review Board of the Fu Jen Catholic University.

\section{Procedures}

\section{Instrumentation}

Eight high-speed infrared cameras (Vicon MX-T20-S+, Oxford Metrics, UK) were set up in the badminton court, which was designed by Tsai, Huang, and Jih (Figure 1). The image capturing frequency was set at $300 \mathrm{~Hz}$. In the court, the front edge of a Kistler force platform (Kistler 9821, Kistler Instrument, Inc., Swiss) was embedded 150 $\mathrm{cm}$ in front of the backcourt boundary. The lateral edge of the platform was aligned with the service line set for playing doubles. The capture frequency of the Kistler force platform was set at $1500 \mathrm{~Hz}$. The racket (Yonex Voltric Z-Force II) had a string tension of 29 pounds. Participants used the shuttlecock (Victor, gaming level) and shoe (Yonex SHBSC2i) suggested by Hsueh, Chen, Pan, and Tsai. Reflective markers were affixed on the rackets and shuttlecocks. The markers were used to determine the heights of the strokes. Vicon Nexus Version 1.8.5 software was used simultaneously to capture the kinematic and kinetic variables while performing the lateral jump smash footwork on the backhand side.

Lateral jump smash trials were conducted using three stroke conditions: shadow (footwork and racket swinging practice without targets), target (footwork and striking a hanging target), and smash (footwork and stroke). The preparatory zone was located on the middle court line (Figure 1, $80 \times 80 \mathrm{~cm}^{2}$ ). The preparatory posture was squatting on both feet, and the rapid movements began from the middle court line. Players moved toward the left side of the court (the backhand side), jumped using both feet, and swung the racket once after a jump stop. After the left foot landed on the force plate, players quickly moved back to the middle of the court line in the preparatory zone. This movement cycle represented one set of complete motion. To ensure the stability of serving motions, before the experiment began, the server would practice the serving movements based on the height of the standing position with both upper limbs stretched upward and the height of the vertical jump of the players. In this study, the server was a badminton player for the Intercollegiate Badminton Open. He stood and served the shuttlecock at a specific serving location based on the smash height of each player. A successful movement meant that the placement after the maximum jump smash by a player was necessarily in zone $B\left(370 \times 100 \mathrm{~cm}^{2}\right)$ (Figure 1).

The initial position of participants was at the center of the right side of the court. The shuttlecock was served from the central line, 120 $\mathrm{cm}$ behind the left serving line, toward the left side of the backcourt. Players served from a $1-\mathrm{m}^{2}$ block. The shuttlecock was served by holding it in the fingertips and standing with both upper limbs extended upward. The height at which the shuttlecock was served was equivalent to the sum of the distance from the ground when a player stood straight with both upper limbs extended upward, 45 to $55 \%$ of the maximum vertical jump height, and the length of the central shaft of a badminton racket $(25 \mathrm{~cm})$. The target shuttlecock was hung at the center of the force plate, a distance of 1.5 times of the leg length of each participant on a line extending along the boundaries in doubles toward the court middle line (greater trochanter to ankle lateral condyle). The height was the most distant point of the fingertips of the upper limbs in the stretching position plus $50 \%$ of the maximum vertical jump height plus $25 \mathrm{~cm}$ (the length of the central shaft of a badminton racket).

Before this study was conducted, the experimental procedures and moves were explained to participants, and participants were asked to sign informed consent forms. The smash, target, and shadow condition tests were conducted for participants in random order. To ensure that athletes gave maximal effort, verbal encouragement was given before the start of each test. Three trials with appropriate moves of racket swinging, target striking, and smashing were required for each participant. After participants 
completed voluntary warm-up exercises and practiced the experimental movements for $5 \mathrm{~min}$, the heights of two repetitions of autonomous maximum jumps were measured. The higher height of the two values was considered the vertical jump height. After calculating the serving height, servers were given sufficient practice time to ensure consistency in serving height. Once all the aforementioned preparations were completed, the formal tests in this experiment were conducted. To avoid lower limb muscle fatigue, participants rested for $1 \mathrm{~min}$ after each trial. The interval between each condition (shadow, target, and smash) was $5 \mathrm{~min}$. Once participants were familiar with the experimental tasks and understood the start signals of the strokes, a total of 51 reflective markers were affixed on the following locations based on the Plug-in-Gait model: the greater trochanter, the inner side of a knee, the inner side of an ankle, and the fifth and first metatarsals. In addition, parameters pertaining to the limbs and the most distant points of the fingertips were estimated. The most distant points of the fingertips were estimated by making participants stand with both hands raised as high as possible and with feet shoulder-width apart. Before participants performed the movement, static data were collected as participants stood on the Kistler force plate in the anatomical position. The static anatomical position files were used to measure body weight. The ankle angle was considered to be $0^{\circ}$ when participants statically stood in the anatomical position. To avoid the experimental errors that may arise because of differences between the capacities of athletes, the experimental scope was as follows. Participants recruited for our study were male badminton players in the Intercollegiate Badminton Open and followed a specific badminton program for 24 weeks, five times per week and $28.7 \pm 3$ hour each week.

Data analysis and reduction

A synchronized trajectory and GRF were estimated using the Nexus Version 1.8.5 Action Analysis System and the Kistler force plate. Visual3D (C-Motion, Rockville, MD, USA) software was used to calculate the kinematic and kinetic variables. The data of the reflective markers were evenly processed using a fourthorder low-pass Butterworth filter set to $8 \mathrm{~Hz}$. After the modules were set by inputting the basic parameters of participants, the angles of the lower limb joints were calculated. The data of the Kistler force plate were processed using a low-pass filter set at $40 \mathrm{~Hz}$ to avoid interference (Sinsurin et al., 2013).

The GRF for each player was standardized using the body weight of players. Furthermore, standardized GRFs (body weight) for different movements were compared. Each variable was estimated by taking an average of three appropriate estimated movements. Previous studies on badminton footwork have suggested that initial contact with the ground during the landing phase is defined as $0 \%$ and the maximum range of the knee flexion occurs at $100 \%$ in the landing phase (Kimura et al., 2012; Yeow et al., 2009).

\section{Statistical analysis}

To examine the differences among various movements, one-way repeated-measures analysis of variance with Bonferroni correction was conducted using the IBM SPSS Software 22.0. Different variables under the shadow condition, target condition, and smash condition that were compared during the impact phase were as follows: 1) the sagittal and frontal joint angle of the hip, knee, and ankle during initial contact with the ground during the landing phase; 2 ) the sagittal and frontal joint angle of the hip, knee, and ankle at maximum knee flexion; 3 ) the range of motion (ROM) in the hip, knee, and ankle during the impact phase; 4 ) the maximum vertical and horizontal GRFs; and 5) time to peak and 50ms impulse during the impact phase. The level of significance was set to $a=.05$.

\section{Results}

Kinematics variables

Table 2 indicates that differences in the center-of-mass velocities at the initial contact with the ground during the landing phase were not significantly different between conditions. The total angle range of knee flexion $\left(-15.27 \pm 3.03^{\circ}\right)$ $(\mathrm{CV}=-19.84)$ under the smash condition was significantly higher than the ranges under the target $\left(-12.74 \pm 3.13^{\circ}\right)(\mathrm{CV}=-24.57)(p=0.004, \mathrm{ES}=$ 0.82 , change $\%=16.57 \%)$ and shadow $(-13.03 \pm$ $\left.2.89^{\circ}\right)(\mathrm{CV}=-22.18)(p=0.010, \mathrm{ES}=0.76$, change $\%$ $=14.67 \%)$ conditions. The knee valgus angles under the smash condition $\left(-8.75 \pm 1.93^{\circ}\right)(\mathrm{CV}=-$ 22.06) were significantly higher than the angles 
under the target $\left(-7.21 \pm 2.17^{\circ}\right)(\mathrm{CV}=-30.10)(p=$ 0.004 , ES $=0.75$, change $\%=17.6 \%)$ and shadow $(-$ $\left.6.93 \pm 2.14^{\circ}\right)(\mathrm{CV}=30.88)(p=0.001, \mathrm{ES}=0.89$, change $\%=20.8 \%$ ) conditions. Under the smash $(39.82 \pm 3.78)(\mathrm{CV}=9.49)$ condition, hip abduction was significantly higher than under the target $(35.58 \pm 6.18)(\mathrm{CV}=17.37)(p=0.001, \mathrm{ES}=0.82$, change $\%=10.65 \%)$ and shadow $(33.50 \pm 5.13)(\mathrm{CV}$ $=15.31)(p=0.001, \mathrm{ES}=1.40$, change $\%=15.87 \%)$ conditions. Moreover, the hip abduction under the target condition was significantly higher than under the shadow $(p=0.017$, ES $=0.37$, change $\%=$ $5.85 \%)$ condition.

Table 3 demonstrates that at the maximum knee flexion, the hip abduction angles were significantly larger under the smash $\left(27.74 \pm 8.66^{\circ}\right)$ $(\mathrm{CV}=31.22)(p=0.038, \mathrm{ES}=0.62$, change $\%=$ $16.00 \%)$ and target $\left(27.08 \pm 7.17^{\circ}\right)(\mathrm{CV}=26.48)(p=$ 0.043 , ES $=0.60$, change $\%=13.96 \%)$ than under the shadow $\left(23.30^{\circ} \pm 5.28^{\circ}\right)(\mathrm{CV}=22.66)$ condition.
Ground reaction force variables

Table 4 reveals that the smash $(0.051 \pm 0.006$ $\mathrm{ms})(\mathrm{CV}=11.76)$ was significantly lower than under the shadow condition $(0.057 \pm 0.010 \mathrm{~ms})$ $(\mathrm{CV}=17.54)(p=0.007, \mathrm{ES}=0.73$, change $\%$ $=10.53 \%$ ).

The vertical GRF was significantly higher under the smash $(5.07 \pm 0.71 \mathrm{BW})(\mathrm{CV}=14.00)$ than the target $(4.54 \pm 0.77 \mathrm{BW})(\mathrm{CV}=16.96)(p=$ 0.041 , ES $=0.71$, change $\%=10.54 \%)$ and the shadow $(4.57 \pm 0.70 \mathrm{BW})(\mathrm{CV}=15.32)(p=0.023$, $\mathrm{ES}=0.72$, change $\%=9.86 \%$ ) condition. The $50-\mathrm{ms}$ GRF impulse was significantly higher under the smash $(1.30 \pm 0.08 \mathrm{BW} \cdot \mathrm{s})(\mathrm{CV}=6.15)$ than that under the target $(1.08 \pm 0.08 \mathrm{BW} \cdot \mathrm{s})(\mathrm{CV}=7.41)(p=$ 0.011 , ES $=2.75$, change $\%=16.92 \%)$ and the shadow condition $(1.03 \pm 0.09 \mathrm{BW} \cdot \mathrm{s})(\mathrm{CV}=8.74)(p$ $=0.004, \mathrm{ES}=3.17$, change $\%=20.77 \%$ ).

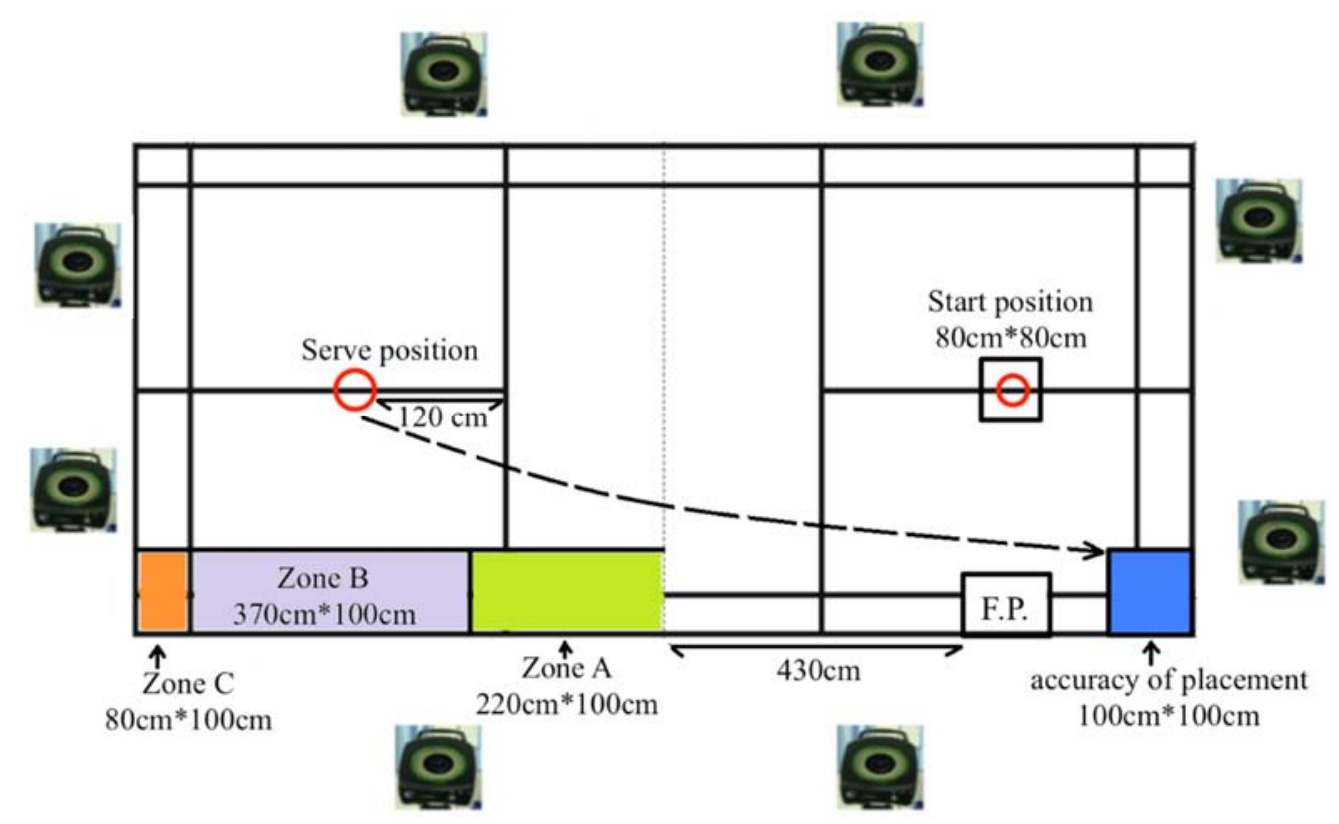

Figure 1

Experimental setup, with the force plate set on the backhand side. Participants performed a single-leg landing on the force plate and returned to the starting position. 


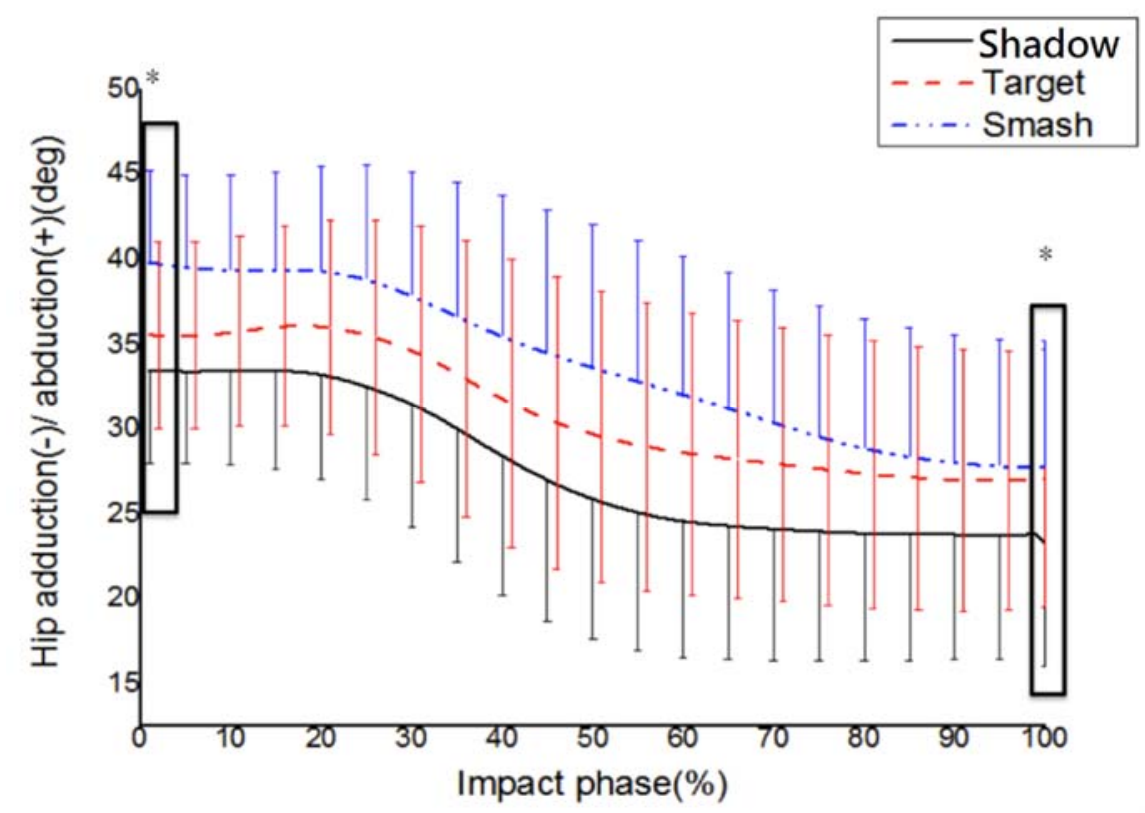

Figure 2A

Degrees of hip movement in the frontal plane under the footwork, target, and smash conditions during the impact phase.

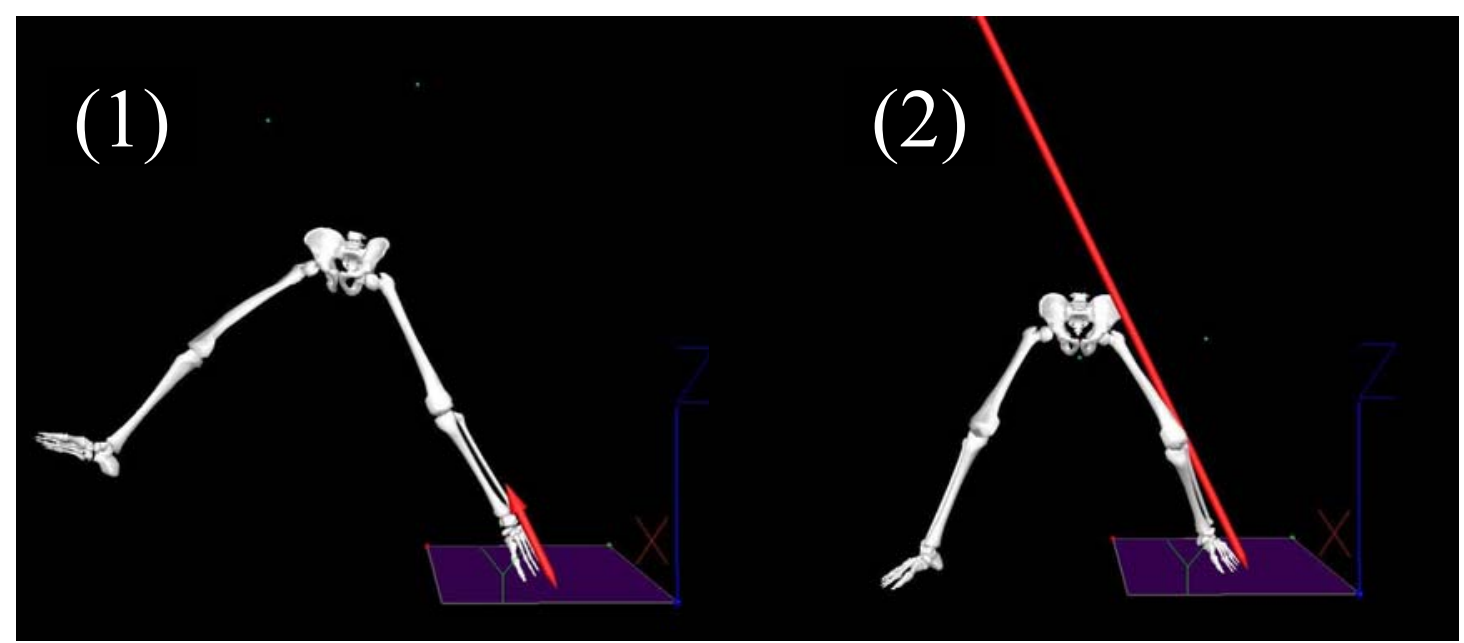

Figure 2B

Hip movement in the frontal plane. (1): At initial contact of the landing phase.

(2): At maximum knee flexion of the landing phase. 


\section{Table 1}

\begin{tabular}{lc}
\multicolumn{2}{c}{ Mean \pm SD of demographic characteristics of participants } \\
\hline Variable & $\mathrm{N}=16$ male athletes \\
\hline Age (years) & $21.1 \pm 1.9$ \\
Height (cm) & $174.3 \pm 4.3$ \\
Body Mass (kg) & $68.4 \pm 6.7$ \\
Fingertips (cm) & $220.9 \pm 6.5$ \\
Maximum Vertical Jump (cm) & $53.1 \pm 5.4$ \\
Target height (cm) & $272.6 \pm 7.3$ \\
Leg Length (cm) & $83.5 \pm 3.1$ \\
Badminton Training Time (hour/week) & $28.7 \pm 3$ \\
Badminton Training Experience (years) & $10.5 \pm 2.4$ \\
\hline
\end{tabular}

Table 2

Mean $\pm S D$ (degree) of kinematic variables of lower extremity joints and center of mass (COM) velocity at initial contact of the landing phase

\begin{tabular}{|c|c|c|c|c|}
\hline Parameter & Shadow & Target & Smash & $F(p)$ \\
\hline $\begin{array}{c}\text { COM velocity }(\mathrm{m} / \mathrm{s}) \\
\mathrm{CV}(\%)\end{array}$ & $\begin{array}{l}1.75 \pm 0.27 \\
\quad(15.42)\end{array}$ & $\begin{array}{l}1.72 \pm 0.25 \\
(14.53)\end{array}$ & $\begin{array}{l}1.84 \pm 0.30 \\
(16.30)\end{array}$ & 1.772 (0.187) \\
\hline \multicolumn{5}{|l|}{ Hip angle } \\
\hline $\begin{array}{c}\text { Extension }(+) / \text { flexion }(-) \\
\text { CV }(\%)\end{array}$ & $\begin{array}{c}-14.54 \pm 3.41 \\
(-23.60)\end{array}$ & $\begin{array}{c}-13.49 \pm 5.76 \\
(-42.70)\end{array}$ & $\begin{array}{c}-13.96 \pm 7.04 \\
(-50.43)\end{array}$ & $0.328(0.723)$ \\
\hline $\begin{array}{c}\text { Abduction (+) / adduction (-) } \\
\text { CV (\%) }\end{array}$ & $\begin{array}{c}33.50 \pm 5.13^{\mathrm{s}, \mathrm{t}} \\
(15.31)\end{array}$ & $\begin{array}{c}35.58 \pm 6.18^{s} \\
(17.37)\end{array}$ & $\begin{array}{c}39.82 \pm 3.78 \\
(9.49)\end{array}$ & $38.943(0.001)$ \\
\hline \multicolumn{5}{|l|}{ Knee angle } \\
\hline $\begin{array}{c}\text { Extension }(+) / \text { flexion }(-) \\
\text { CV }(\%)\end{array}$ & $\begin{array}{c}-13.03 \pm 2.89 \\
(-22.18)\end{array}$ & $\begin{array}{c}-12.74 \pm 3.13 \\
(-24.57)\end{array}$ & $\begin{array}{c}-15.27 \pm 3.03^{\mathrm{t}, \mathrm{f}} \\
(-19.84)\end{array}$ & $11.625(0.001)$ \\
\hline $\begin{array}{c}\text { Varus (+) / valgus (-) } \\
\text { CV (\%) }\end{array}$ & $\begin{array}{c}-6.93 \pm 2.14 \\
(-30.88)\end{array}$ & $\begin{array}{c}-7.21 \pm 2.17 \\
(-30.10)\end{array}$ & $\begin{array}{l}-8.75 \pm 1.93^{\mathrm{t}, \mathrm{f}} \\
\quad(-22.06)\end{array}$ & $17.876(0.001)$ \\
\hline $\begin{array}{c}\text { Ankle angle } \\
\text { Plantar-flexion (+) / dorsi- } \\
\text { flexion (-) } \\
\text { CV (\%) }\end{array}$ & $\begin{array}{c}28.19 \pm 2.92 \\
(10.36)\end{array}$ & $\begin{array}{c}27.82 \pm 1.88 \\
(6.76)\end{array}$ & $\begin{array}{c}27.53 \pm 2.82 \\
(10.24)\end{array}$ & $0.721(0.495)$ \\
\hline $\begin{array}{c}\text { Inversion }(+) / \text { eversion }(-) \\
\mathrm{CV}(\%)\end{array}$ & $\begin{array}{c}-3.55 \pm 4.01 \\
(-112.96)\end{array}$ & $\begin{array}{c}-3.33 \pm 4.15 \\
(-124.62)\end{array}$ & $\begin{array}{c}-3.15 \pm 4.42 \\
(-140.32)\end{array}$ & $0.327(0.724)$ \\
\hline
\end{tabular}

f Significant difference with shadow training $(p<.05)$

t Significant difference with target striking $(p<.05)$

s Significant difference with smashes $(p<.05)$ 
Table 3

Mean \pm SD (degree) range of motion in lower extremity joints at maximum knee flexion

\begin{tabular}{ccccc}
\hline Variable & Shadow & Target & Smash & $F(p)$ \\
\hline Hip angle & & & & \\
Extension (+) / flexion (-) & $-52.35 \pm 9.24$ & $-49.67 \pm 11.46$ & $-52.28 \pm 9.22$ & $1.893(0.168)$ \\
CV (\%) & $(-17.65)$ & $(-23.07)$ & $(-17.64)$ & \\
& & & & \\
Abduction (+) / adduction (-) & $23.30 \pm 5.28$ t, & $27.08 \pm 7.17$ & $27.74 \pm 8.66$ & $(31.22)$ \\
CV (\%) & $(22.66)$ & $(26.48)$ & & \\
Knee angle & & & \\
Extension (+) / flexion (-) & $-68.04 \pm 4.83$ & $-67.39 \pm 6.01$ & $-68.26 \pm 4.83$ & $0.382(0.686)$ \\
CV (\%) & $(-7.10)$ & $(-8.92)$ & $(-7.08)$ & \\
Varus (+) / valgus (-) & $-11.66 \pm 5.64$ & $-11.39 \pm 4.85$ & $-12.94 \pm 4.93$ & $2.407(0.107)$ \\
CV (\%) & $(-48.37)$ & $(-42.58)$ & $(-38.10)$ & \\
Ankle angle & & & \\
CV (\%) & $-25.23 \pm 6.03$ & $-25.90 \pm 4.68$ & $-26.46 \pm 5.17$ & $1.089(0.349)$ \\
Plantar-flexion (+) / dorsi-flexion (-) & $(-23.90)$ & $(-18.06)$ & $(-19.54)$ & \\
CV (\%) & $-5.37 \pm 4.78$ & $-5.01 \pm 4.36$ & $-4.82 \pm 4.24$ & $0.216(0.807)$ \\
Inversion (+) / eversion (-) & $(-89.01)$ & $(-87.03)$ & $(-87.97)$ & \\
\hline
\end{tabular}

fSignificant difference with shadow training $(p<.05)$

${ }^{t}$ Significant difference with target striking $(p<.05)$

${ }^{s}$ Significant difference with smashes $(p<.05)$

Table 4

Mean $\pm S D$ ground reaction force and time to peak during the impact phase

\begin{tabular}{|c|c|c|c|c|}
\hline Parameter & Shadow & Target & Smash & $F(p)$ \\
\hline $\begin{array}{c}\text { Time to peak (s) } \\
\text { CV }(\%)\end{array}$ & $\begin{array}{c}0.057 \pm 0.010 \\
(17.54)\end{array}$ & $\begin{array}{l}0.055 \pm 0.010 \\
(18.18)\end{array}$ & $\begin{array}{l}0.051 \pm 0.006^{\mathrm{f}} \\
\quad(11.76)\end{array}$ & $7.836(0.002)$ \\
\hline $\begin{array}{c}\text { Vertical GRF (BW) } \\
\text { CV (\%) }\end{array}$ & $\begin{array}{c}4.57 \pm 0.70 \\
(15.32)\end{array}$ & $\begin{array}{c}4.54 \pm 0.77 \\
(16.96)\end{array}$ & $\begin{array}{c}5.07 \pm 0.71^{\mathrm{t}, \mathrm{f}} \\
(14.00)\end{array}$ & $6.462(0.005)$ \\
\hline $\begin{array}{c}\text { Horizontal GRF (BW) } \\
\text { CV (\%) }\end{array}$ & $\begin{array}{l}2.11 \pm 0.40 \\
(18.96)\end{array}$ & $\begin{array}{l}2.24 \pm 0.53 \\
(23.66)\end{array}$ & $\begin{array}{c}2.17 \pm 0.33 \\
(15.21)\end{array}$ & $0.597(0.557)$ \\
\hline $\begin{array}{c}\text { 50ms impulse }(\mathrm{BW} \cdot \mathrm{s}) \\
\mathrm{CV}(\%)\end{array}$ & $\begin{array}{c}1.03 \pm 0.09 \\
(8.74)\end{array}$ & $\begin{array}{c}1.08 \pm 0.08 \\
(7.41)\end{array}$ & $\begin{array}{c}1.30 \pm 0.08^{\mathrm{t}, \mathrm{f}} \\
(6.15)\end{array}$ & $10.822(0.001)$ \\
\hline
\end{tabular}

fSignificant difference with shadow training $(p<.05)$

${ }^{t}$ Significant difference with target striking $(p<.05)$

${ }^{s}$ Significant difference with smashes $(p<.05)$ 


\section{Discussion}

This study aimed to explore the applications of landing strategies while performing smashes, target striking, and shadow training in badminton. The main findings of this study indicate that during the landing impact phase, smash motions have large hip abduction, high vertical GRF, large 50-ms passive impulse, and short vertical GRF time to peak in the smash.

In this experiment, the ranges of knee flexion at initial contact with the ground, the angles of knee valgus, and hip abduction were significantly higher under the smash condition than those under the target and shadow conditions. Hip abduction was higher in target striking than in shadow training. In previous studies, landing tests have been conducted for both genders, and the results were compared. Those results specified that females had a higher frontal ROM of the knee joints on the landing, which could cause higher risks of ACL injuries in females than in males. The landing moves of male and female volleyball players in college have been compared. At the maximal knee flexion, the angles of knee valgus were larger in females than in males (Hughes et al., 2008; Kernozek et al., 2005). Sinsurin et al. (2013) conducted landing tests on 18 male baseball and volleyball players under four landing conditions, i.e., forward jump landing $\left(5.8^{\circ}\right)$, diagonal $30^{\circ}$ jump landing $\left(7.5^{\circ}\right)$, diagonal $60^{\circ}$ jump landing $\left(7.7^{\circ}\right)$, and lateral $90^{\circ}$ jump landing $\left(8.8^{\circ}\right)$. The results indicated that the lateral jump landing caused the largest knee valgus angles. However, this study only focused on the angles of the knee joints, without exploring the range changes in the ankle and hip joints (Sinsurin et al., 2013). Kimura et al. (2012) analyzed the backhand footwork motions in the backcourt for female badminton players. They found that after a backhand smash in the backcourt, the angles of knee valgus and hip abduction were the highest at the initial contact with the ground during the landing phase. These angles could increase the load on the ACL for badminton players. In addition to the differences in the angles in the frontal flexion and extension, a higher range of knee flexion was found at the initial contact with the ground while landing. This athletic biomechanical mechanism was probably caused by activation of the neuromuscular system to absorb the landing impact. Findings of this study pertaining to the smash action during the landing were in line with the findings of previous studies. When a subject landed on the floor, the flexion angles of the knee joints increased. The increase in knee flexion angles activated the quadriceps and reduced the load on the ACL while landing (Chappell et al., 2007). Kimura et al. (2012) analyzed the backhand footwork in the backcourt for badminton players. When the maximum knee flexion angle was reached, the flexion angles of both hip and knee joints and the valgus angles of the knee joints were larger on the backhand than on the forehand side. In this study, the hip abduction angles were larger under the smash and target conditions than in shadow training. These results are not consistent with the results of the study of Kimura et al. (2012). This inconsistency was possibly because of the differences in the experimental design. Since badminton involves unilateral strikes, the racket swinging actions of the upper limbs could also affect landing postures. This study focused on the backhand landing tests under different conditions, unlike the study by Kimura et al. (2012), in which variables in the backhand and forehand sides were compared.

In view of the influence of height on landing strategies, previous research has focused on landing tests at heights of $30 \mathrm{~cm}$ and $60 \mathrm{~cm}$ in 18 healthy male basketball players. Their results indicated that excessive increases in hip frontal actions and greater decreases in ROM of knee flexion and extension would cause higher loading of the lower limb joints (Yeow et al., 2009). In this study, the knee valgus and hip abduction at the initial contact with the ground during landing were higher in the smashes than in target striking and shadow training. At the maximum range of knee flexion, the angles of hip abduction were larger under the smash and target than the shadow condition.

Previous research has reported that preparing for landing with the knee in valgusvarus and internal-external rotation positions and the hip in abduction-adduction and internalexternal rotation positions may affect ACL loading. After badminton players performed lateral smashes, higher knee valgus angles were observed at the initial contact with the ground while landing. Concurrently, larger angles of knee flexion were also observed. Such angles could 
reduce the load on the ACL caused by the forward shear of the tibias (Chappell et al., 2007).

Players may be able to avoid excessive loads on the lower limb joints by employing different landing postures. This study suggests that a larger angle of knee valgus was estimated during the smash action. However, appropriate knee flexion and extension could be applied to absorb the impact while landing. Therefore, neuromuscular training for the knee flexors and extensors could be included in routine training to reduce the risk of knee injuries. Therefore, future studies on badminton footwork could investigate different cutting and jumping directions after landing to further understand how smash directions and motor patterns might increase the load on the lower limbs.

\section{Ground reaction force}

As the landing height increased, the peak value of the vertical GRF increased, causing a high load on the lower limb joints (Yeow et al., 2009). The results of the present study indicate that a high passive impulse occurs at initial contact with the ground during the landing phase. The human body can reduce the impact while landing by performing lower limb muscle contraction with joint flexion. However, this biomechanical mechanism cannot be activated immediately. In previous studies, the reaction time of the neuromuscular system in human bodies has been found to be 50-75 ms. However, if the landing is completed within $50 \mathrm{~ms}$, the GRF impact cannot be efficiently nullified using this mechanism. If the impact is greater than the loading of joints and ligaments, the risk of joint and ligament injuries increases (Cabello-Manrique and Gonzalez-Badillo, 2003; Dufek and Bates, 2009; Nigg, 1985).

This study found that after the lateral jump smash, the time to peak ranged from 51 to $57 \mathrm{~ms}$. The peak values of the vertical reaction force were four to five times body weight. The peak values of the horizontal GRF were twice body weight. However, in practical situations, players would probably exert a higher GRF and have shorter time to peak. By conducting neuromuscular training, the landing technique can be improved to prevent lower limb injuries caused by strong floor impacts (Irmischer et al., 2004; Marquez et al., 2009; Wikstrom et al., 2008).

In this study, the time to peak was significantly lower under the smash than the target and shadow conditions $(\mathrm{p}<.05)$. With appropriate footwork training, players could spend more time to reach the ground during the landing phase, thereby lowering the GRF. Previous research (Marquez et al., 2009) analyzed the GRF during jump spike actions in volleyball. The vertical GRF caused by jump spike actions was approximately 9-11 times body weight. The peak horizontal GRF was approximately twice body weight. The time to peak of the vertical GRF was at approximately $31-37 \mathrm{~ms}$. Although, there were some differences between that previous study and this research, also some similar landing patterns between the two sports may be found. In volleyball, landing movements of jump spikes that the player lands after the maximal or submaximal jump, are such that one of the legs contacts the ground firstly and the other leg follows soon after. In badminton the process is similar. The only difference consisted in the GRF which resulted from the jump height of our testing requirement.

The one-foot landing patterns were performed by badminton players after lateral jump smash actions. This landing pattern significantly increased the load on the lower limb joints. However, kinetic variable results revealed that when players were trained for racket swinging, a lower load was exerted on the lower limb joints.

\section{Conclusions}

Footwork training is one of the few singlepersonal training programs in badminton. The contents of the program usually involve repetitive work which not only could strengthen the lower extremity flexor-extensor muscles, but also enhance the neural motor adaptation skills. This research found significant differences in landing strategies in the smash and shadow training of badminton players. Smash movements caused greater lateral loading in the lower limbs, which decreased lower-limb joint control. In addition to shadow training, core muscle reinforcement and neuromuscular training of the hip abduction and adduction in the lower limbs could enhance muscle control in the lower extremities and prevent lower limb joint injuries. To improve the muscle potential and capabilities, the agility ladder or plyometric training should be included in the training program. In this research, a 
shuttlecock was served at a target located in a single fixed position for participants to strike. It was found that striking the target could affect the landing strategies used by players. The landing strategies after target striking were relatively similar to those after smashes, compared with those after shadow training. In future research, the target position can provide the setting of training for badminton players' specific performance ability to find the most suitable swing target height and lateral distance.

\section{Acknowledgements}

This research was supported by the National Science Council in Taiwan (MOST 108-2410-H-179-007-). This research did not receive any specific grant from funding agencies in the public, commercial, or not-forprofit sectors.

\section{References}

Arendt E, Dick R. Knee injury patterns among men and women in collegiate basketball and soccer. NCAA data and review of literature. Am J Sports Med, 1995; 23: 694-701

Boden BP, Torg JS, Knowles SB, Hewett TE. Video analysis of anterior cruciate ligament injury. Am J Sports Med, 2009; 37: 252-259

Chappell JD, Creighton RA, Giuliani C, Yu B, Garrett WE. Kinematics and electromyography of landing preparation in vertical stop-jump: Risks for noncontact anterior cruciate ligament injury. Am J Sports Med, 2007; 35: 235-241

Cabello-Manrique C, Gonzalez-Badillo JJ. Analysis of the characteristics of competitive badminton. $\mathrm{Br} J$ Sports Med, 2003; 37: 62-66

Coventry E, O'Connor KM, Hart BA, Earl JE, Ebersole KT. The effect of lower extremity fatigue on shock attenuation during single-leg landing. Clin Biomech, 2006; 21: 1090-1097

Dufek JS, Bates BT. Biomechanical factors associated with injury during landing in jump sports. Sports Med, 2009; 12: 326-337

$\mathrm{Fu}$ L, Ren F, Baker JS. Comparison of joint loading in badminton lunging between professional and amateur badminton players. Appl Bionics Biomech, 2017. doi: 10.1155/2017/5397656

Goh SL, Mokhtar AH, Mohamad Ali MR. Badminton injuries in youth competitive players. J Sports Med Phys Fitness, 2013; 53: 65-70

Hewett TE, Myer GD, Ford KR, Heidt RS, Colosimo AJ, McLean SG, Succop P. Biomechanical measures of neuromuscular control and valgus loading of the knee predict anterior cruciate ligament injury risk in female athletes. Am J Sports Med, 2005; 33: 492-501

Hsueh YC, Chen YY, Pan KM, Tsai CL. Biomechanical Analysis on badminton Forehand Dab Shot and Stab Shot. Phys Edu J, 2013; 46: 351-362

Hughes G, Watkins J, Owen N. Gender differences in lower limb frontal plane kinematics. Sports Biomech, 2008; 7: 333-341

Hughes G, Watkins J, Owen N. Differences between the sexes in knee kinetics during landing from volleyball block jumps. Eur J Sport Sci, 2010; 10: 1-11

Irmischer BS, Harris, C, Pfeiffer RP, DeBeliso MA, Adams KJ, Shea KG. Effects of a knee ligament injury prevention exercise program on impact forces in women. J Strength Cond Res, 2004; 18: 703-707

Kanasova J, Czakova N, Divinec L, Veis A, Solvesterova M. Impact of balance exercises on the elimination of functional muscular disorders in volleyball players. Phys Activ Rev, 2019; 7:152-159

Kernozek TW, Torry MR, Hoof HV, Cowley H, Tanner S. Gender differences in frontal plane and sagittal plane biomechanics during drop landings. Med Sci Sports Exerc, 2005; 37: 1003-1012

Kimura Y, Ishibashi Y, Tsuda E, Yamamoto Y, Tsukada H, Toh S. Mechanisms for anterior cruciate ligament injuries in badminton. Br J Sports Med, 2010; 44: 1124-1127 
Kimura Y, Ishibashi Y, Tsuda E, Yamamoto Y, Hayashi Y, Sato S. Increased knee valgus alignment and moment during single-leg landing after overhead stroke as a potential risk factor of anterior cruciate ligament injury in badminton. Br J Sports Med, 2012; 46: 207-213

Kuntze G, Mansfield N, Sellers W. A biomechanical analysis of common lunge tasks in badminton. J Sports Sci, 2010; 28: 183-191

Koga H, Nakamae A, Shima Y, Iwasa J, Myklebust G, Engebretsen L, Krosshaug T. Mechanisms for noncontact anterior cruciate ligament injuries: knee joint kinematics in 10 injury situations from female team handball and basketball. Am J Sports Med, 2010; 38: 2218-2225

Krosshaug T, Nakamae A, Boden BP, Engebretsen L, Smith G, Slauterbeck J. R, Bahr R. Mechanisms of anterior cruciate ligament injury in basketball: video analysis of 39 cases. Am J Sports Med, 2007; 35: 359-367

Madsen CM, Karlsen A, Nybo L. Novel speed test for evaluation of badminton-specific movements. J Strength Cond Res, 2015; 29: 1203-1210

Mandelbaum BR, Silvers HJ, Watanabe DS, Knarr JF, Thomas SD, Griffin LY, Garrett Jr W. Effectiveness of a neuromuscular and proprioceptive training program in preventing anterior cruciate ligament injuries in female athletes: 2-year follow-up. Am J Sports Med, 2005; 33: 1003-1010

Marquez WQ, Masumura M, Ae M. The effects of jumping distance on the landing mechanics after a volleyball spike. Sports Biomech, 2009; 8: 154-166

Mcnitt-Gray JL. Kinematics and impulse characteristics of drop landings from three heights. Sports Biomech, 1991; 7: 201-224

Miyake E, Yatsunami M, Kurabayashi J, Teruya K, Sekine Y, Endo T, Nishida R, Takano N, Sato S, Kyung $\mathrm{HJ}$. A prospective epidemiological study of injuries in Japanese national tournament-level badminton players from junior high school to university. Asian J Sports Med, 2016; 7(1): e29637

Nigg BM. Biomechanics, load analysis and sports injuries in the lower extremities. Sports Med, 1985; 2: 367379

Nagano Y, Sasaki S, Higashihara A, Ichikawa H. Movements with greater trunk accelerations and their properties during badminton games. Sports Biomech, 2018; 1-11

Petersen W, Braun C, Bock W, Schmidt K, Weimann A, Drescher W, Zantop T. A controlled prospective case control study of a prevention training program in female team handball players: the German experience. Arch Orthop Trauma Surg, 2005; 125(9): 614

Reeves J, Hume PA, Gianotti S, Wilson B, Ikeda E. A Retrospective Review from 2006 to 2011 of Lower Extremity Injuries in badminton in New Zealand. Sports, 2015; 3(2): 77-86

Schmitz RJ, Kulas AS, Perrin DH, Riemann BL. Sex differences in lower extremity biomechanics during single leg landings. Clin Biomech, 2007; 22: 681-688

Shariff A, George J, Ramlan A. Musculoskeletal injuries among Malaysian badminton players. Singapore Med J, 2009; 50: 1095-1097

Sinsurin K, Vachalathiti R, Jalayondeja W, Limroongreungrat W. Altered peak knee valgus during jumplanding among various directions in basketball and volleyball athletes. Asian J Sports Med, 2013; 4(3): 195

Stephenson ML, Hinshaw TJ, Wadley HA, Zhu Q, Wilson MA, Byra M, Dai B. Effects of timing of signal indicating jump directions on knee biomechanics in jump-landing-jump tasks. Sports Biomech, 2017; 116

Sasaki S, Nagano Y, Ichikawa H. Loading differences in single-leg landing in the forehand- and backhandside courts after an overhead stroke in badminton: A novel tri-axial accelerometer research, J Sports Sci, 2018; 1-8

Tsai CL, Huang CF, Jih SC. Biomechanical Analysis of Four Different badminton Forehand Overhead Strokes. Phys Edu J, 1997; 22: 189-200 
Wikstrom EA, Tillman MD, Schenker SM, Borsa PA. Jump-landing direction influences dynamic postural stability scores. J Sci Med Sport, 2008; 11: 106-111

Weir MA, Watson AWS. A twelve month study of sports injuries in one Irish school. Ir J Med Sci, 1996; 165: 165-169

Yung PSH, Chan RHK, Wong FCY, Cheuk PWL, Fong DTP. Epidemiology of injuries in Hong Kong elite badminton athletes. Res Sports Med, 2007; 15: 133-146

Yeow $\mathrm{CH}$, Lee PVS, Goh JCH. Effect of landing height on frontal plane kinematics, kinetics and energy dissipation at lower extremity joints. J Biomech, 2009; 42: 1967-1973

\section{Corresponding author:}

\section{Chin-Shan Ho, Ph.D.}

Graduate Institute of Sports Science, National Taiwan Sport University No. 250, Wenhua 1st Rd., Guishan Township, Taoyuan County 33301, Taiwan (ROC)

Phone numbers: 886-3-328-3201\#2619

Fax numbers: 886-3-328-0592

E-mail address: kilmur33@gmail.com 